\title{
FURTHER POINTS IN THE PHYSIOLOGY OF BRAIN SURGERY.*
}

\author{
By CeCil E. REYNolds, Los Angeles, Cal.
}

IN a previous paper I endeavoured to illustrate the importance of twostage operations and the influence of posture both during and after brain operations upon the phenomena of shock and convulsions. I now submit a few further observations relative to the physiology and mechanics of brain surgery.

\section{CRANIECTOMY.}

There are two modes of approach to the various regions of the brain. One is removal of a greater or less amount of bone, and the other is the fashioning of a neat bevel-edged window. As is well known, the bone is completely removed from the subtemporal region in Cushing's operation for the relief of positive pressure in cases of irremovable tumours and other conditions, but the advent of ventriculography, whilst tending toward the ideal of complete extirpation in a larger percentage of tumours, has not supplanted the usefulness of decompression to anything like the extent that some believe, as I hope now to show.

Complete removal of bone is also the preferable operation in the suboccipital region, because it is much easier and quicker than the making of an osteoplastic flap in this region and allows more natural adjustments. Within a few months such a firm fibrous hammock has been formed between the muscles and the arachnoid cistern that the deepest palpation cannot distinguish the condition from the normal. In the frontal and parietal regions it is the proper aim to form an osteoplastic flap with bevel edges that will allow restitution in statu quo ante. Such a flap, properly formed, is completely invisible by $x$-ray examination in about five years.

Now there are certain important exceptions to this latter ideal which deserve more attention than has been given to them; in fact I cannot find specific mention of these conditions from this standpoint in the literature.

Possibly brain surgeons have considered them mere matters of common sense. The first of these points is that one cannot in any case

* Read before the 53rd Convention of the Medical Society of the State of California, Los Angeles, May, 1924. 
with safety replace a perfect bone flap over a cavity, and in the aged one cannot with safety replace a bone flap entire over even a slight chronic negative pressure. This does not mean that in all cases of negative pressure the entire bone flap must be removed and the scalp placed next to the membranes, although in many instances this is necessary; but that at least a portion of bone must be left out at the most sheltered portion of the field of abnormality, of such a size as will permit the scalp to be pressed in enough to limit the pulsation. Nature abhors a vacuum, especially within the cranium, in which place air is a relative vacuum, as occurs under conditions in which there is insufficient cerebrospinal fluid to fill the cavity.

Let us consider some concrete cases : for example, a large extradural hæmorrhage from the middle meningeal artery.

Within twenty-four hours the brain will have become considerably compressed, so that removal of the clot leaves a hollow as large as a teacup. Therefore removal of this clot from beneath an osteoplastic flap leaves a cavity which may not be completely obliterated for several hours. Since in this case the dura has not been opened, there is not the same risk of rupture of the cerebral arteries as in the instances to be presently described, but if the bone flap is replaced entire and the patient laid recumbent, there is a mechanical pull on the medulla, and also a too rapid suction upon the fourth ventricle by the expansion of the lateral ventricle which was formerly compressed. Under these circumstances I have seen very sudden death. Such an accident can be avoided by keeping the head somewhat raised under watchful supervision, after leaving out sufficient bone to regulate expansion of the lateral ventricle by pressure inward of a dressing upon the yielding scalp.

The end-results in a great variety of diseased conditions of the brain appear to be better when a certain amount of bone has been left out-for example, in cases of senile local atrophy of the brain, of which the symptoms and effects appear to have attracted little attention. From causes which are usually not clear, some elderly people develop medically incurable and distressing symptoms due to local brain shrinkage, which sometimes may be diagnosed by $x$-ray, but usually cannot be determined without exploratory operation. The local atrophy of the brain is commonly associated with adhesions of the very thin dura to the inner table of the skull. The resulting vacuum is filled in with a local accumulation of subarachnoid fluid. Now, subarachnoid fluid is a more fluctuating medium than healthy brain and it is apt, under circumstances of fatigue or dehydration, to drain away into the basal cisterns. When this occurs there is a pull upon the unduly adherent dura, causing intolerable headache, and, in time, additional defect in cortical function.

Surgical interference in these cases may or may not benefit the 
defect in cerebral function, but it does cure the headache, provided the bone is left out. If the bone flap is replaced, the headache will probably recur, or the patient may die within a few hours from arterial rupture due to vacuum. The following cases illustrate these points.

CASE I.-A man of seventy suffered from frontal headache, continuous and distressing spasmodic torticollis, and progressive dementia, all said to have followed a street accident. $X$-ray showed a shadow in the left frontal region.

Beneath the dura was a very evident arachnoid cyst. The negative pressure after drainage was not very marked, so I replaced the bone flap, leaving an unstuffed cigarette drain beneath it. Twenty hours later the patient was in excellent condition and free from headache and torticollis, when an incautious nurse asked him to raise his hips while she pulled the sheet. He at once felt a shock in the head and quickly lapsed into coma. Autopsy showed that several large arteries had ruptured in the frontal lobe. Had the bone been left out and compression applied over the scalp, this might have been avoided.

CASE II.-Accordingly, when another man of over seventy came complaining of severe pain above the left eye and progressive motor aphasia, and the $x$-ray showed a notable density in the Broca region, I removed the bone entirely over the anterior part of the temporal lobe, over Broca's area, and above the left frontal sinus. There was a cystic condition beneath the dura, and, in order to guard against overpulsation of the released brain, a flap of temporal muscle was turned upwards and stuffed into the cavity above the eyebrow. This was especially necessary as the bone was abnormally thick and the dura unduly adherent to it and so thin that it had largely come away with the rongueur (a very unusual circumstance). The patient made an excellent recovery and has remained free from pain and improved in speech. The Wassermann reaction in this case was reported as " suspicious plus."

CASE III.-In another case in which I had been compelled to leave out a considerable amount of bone in the frontotemporal region after resection of the entire right frontal pole for glioma, an additional advantage presented itself when the patient came two years later with a return of symptoms. Owing to the defect in the skull, it was possible at once to determine that he had a secondary cyst and not an extension of solid growth. Evacuation relieved his symptoms.

\section{SPONTANEOUS APOPLEXY.}

Three operations for the relief of spontaneous apoplexy also serve to illustrate this point in technique.

CASE IV.- - Last year I was called to see a woman at the Glendale hospital, who, following childbirth three weeks earlier, had for the previous two days suffered from almost continuous fits, in which the head 
and eyes were jerked to the left, and she had also a leftsided hemiplegia. She soon lapsed into status and coma. On turning down a right parietal osteoplastic flap, there was found beneath the dura a subarachnoid hæmorrhage covering the entire frontoparietal region. The cerebral veins were thrombosed, and the great additional intracerebral pressure led me to explore subcortically and thus evacuate an unsuspected subcortical clot. The bone was removed entirely and the scalp-periosteal flap sewn back over the replaced dura, which was not stitched. The patient made an uninterrupted recovery, has never had a fit since the operation, and the hemiplegia cleared up completely. Her mentality is also normal.

This method of procedure was largely dictated by the course of an earlier case of spontaneous apoplexy upon which $I$ operated at the California Hospital two years ago.

CASE V.-When I first saw this woman she was profoundly comatose, with evidence of leftsided hemiplegia, the symptoms having commenced thirty-six hours earlier. On turning down a similar flap over the right parietal region, the same condition of subarachnoid hæmorrhage over the entire right hemisphere was apparent. In this instance I replaced the osteoplastic flap and merely left a subtemporal decompression below it. A flat drain was brought out at one angle and the head kept very low to favour thorough washing by cerebrospinal fluid. The patient continued to have leftsided fits and remained in coma for about two weeks, but thereafter completely recovered, both in power of all limbs and mentality. However, she has since had Jacksonian fits of the mouth and jaw to the left three or four times a month.

It is evident, therefore, that of these two acute cases, the patient in whom the bone was left out entirely made a better recovery in spite of the fact that there was an additional subcortical clot and more intravascular thrombosis.

CASE VI.-As a further example, in a chronic case of apoplexy, G. D., at the age of three years, had a sudden rightsided hemiplegia, followed by fits which continued until I saw him at the age of eleven. He was then having several fits a week, and was imbecile, with severe hemiplegia and contractures.

On turning down a left parietal osteoplastic flap, a large teacupful of chocolate-coloured fluid was evacuated from beneath the dura, and the hemisphere looked flattened almost to the falx. Obviously it was impossible to replace any of the bone, so the very large flap of bone was peeled off and the scalp allowed to sink into the cavity.

The boy has never had a fit since the operation, three years ago ; his mentality is remarkably improved, so that he attends school with normal boys, and the gait is slightly improved. No pulsation can be felt in the decompression area, which is quite firm. 


\section{POINTS IN DIAGNOSIS.}

Before leaving the subject of extracerebral hæmorrhages, there are some points in diagnosis worth mentioning.

To distinguish between subarachnoid and extradural hæmorrhage is not always easy. Rupture of the middle meningeal trunk not infrequently occurs without any fracture of the bone. In the last few years I have had two such cases, in which the violence was very trivial indeed, scarcely noticed by the patient, and the skull was intact.

In the first case I was consulted too late to do any good, for, although the diagnosis was made and the clot evacuated, the longitudinal sinus was completely thrombosed from prolonged stagnation of the contained blood.

CASE VII.-The second case, without fracture or appreciable injury, was referred early by Dr. Piersol, of Pomona. The physical signs were as follows: Left sixth nerve, paralysis; right third nerve, paralysis ; right pupil, fully dilated ; left pupil, half contracted. Optic discs, normal ; veins, large. No definite paresis of any limb, but the gait was spastic and ataxic, the patient having to be supported as he staggered in a semistuporous condition. Knee jerks moderately exaggerated and equal ten hours from the onset, but the left knee jerk had been abolished six hours earlier. No ankle clonus. Plantar reflexes normal. All limbs rigid during sleep.

Semi-coma slowly deepening. Rigors present but no sign of fits.

Blood pressure 145/80. Pulse 54. Headache and vomiting.

Spinal puncture settled the diagnosis very definitely. Removal of 25 c.c. of clear colourless fluid under low pressure caused, first, a disappearance of the left sixth nerve paresis, and then, half an hour later, a more rapid development of profound coma. Moreover, the pulse dropped from 54 to 44.

It was evident that the quick relief of pressure obtained by spinal puncture, as attested by return of function of the left external rectus muscle, was followed by a more steady and accelerated increase of pressure. In other words, the abstraction of spinal fluid had augmented the bleeding from some intracranial vessel. It was also evident that the ophthalmoplegia could not be explained by a nuclear lesion, because a lesion in the midbrain capable of causing such general intracranial pressure would inevitably produce bilateral ophthalmoplegia.

Also, since the spinal fluid was free from blood, it was more than likely that the hæmorrhage was extradural, and so it proved.

The very large extradural clot was over the right hemisphere and extended round the base to the cavernous sinus. After evacuation, the boy made a rapid and complete recovery, but the bone was left out in the lower subtemporal region.

This case illustrates two other points in the differential diagnosis, 
viz., that extradural hæmorrhage is much less frequently accompanied by convulsions than is subarachnoid bleeding, except in children. This can be readily understood because in subarachnoid hæmorrhage there is not only pressure, but contractile adhesiveness as well, upon the cortex. The actual pressure, however, is never as great as in extradural bleeding, as a rule, partly because in subarachnoid bleeding the patients succumb earlier. Further, the symptoms are slower in their onset in extradural hæmorrhage.

In all convulsive cases the head and eyes are jerked away from the side of the lesion for a variable number of hours, but eventually the eyes turn constantly towards the side of the lesion, if relief has not been obtained. When the eyes remain turned toward the side of the lesion, with deep coma, the prospect of recovery after operation is quite poor.

Another condition which is difficult to distinguish from subarachnoid hæmorrhage is that of acute toxic convulsions with coma. It is here that I have been frequently helped by the knowledge that in toxic cases the convulsions most are liable to be on the right side in righthanded persons, and vice versâ, just as occurs in general increase of subdural and subarachnoid fluid. In other words, the dominant hemisphere is the earlier to rebel in general and evenly distributed conditions. Intraventricular pressure is not an evenly distributed condition, because the inner table of the skull is not uniformly smooth.

It will be remembered that, in the cases of the two women referred to above as suffering from subarachnoid hæmorrhages, the fits and paresis were on the left side of the body while the patients were righthanded, so that general toxæmia was not the presumptive diagnosis even before detailed examination. The dilatation and fixation of the pupil on the side of the lesion is also of great assistance in cases of hæmorrhage. I cannot remember this to have occurred in a toxic case except as a transient condition.

Both classes are liable to Jacksonian fits, but the paralysis due to hæmorrhage soon declares itself as more profound and lasting than the paresis due to a toxic Jacksonian fit alone. This fact, however, is apt to be obscured by the coma which supervenes in both types. The optic dises are of very little value in distinguishing the two conditions. There has been ample opportunity for studying toxic convulsions since the advent of prohibition, for "moonshine" and "home-brew" seem to be peculiarly convusive in their action.

\section{POINTS IN TECHNIQUE.}

In conclusion, mention may be made of the special points of technique laid down by the late Sir Victor Horsley, which I have found it unwise ever to depart from. In the first place, he used chloroform by the Vernon Harcourt method, which allows a maximum of 2 per cent. of 
chloroform in air, the average required percentage being 1 per cent. Having returned to this method during the last year, after using ether for several years, I can unhesitatingly affirm that there is no comparison in point of safety for brain operations. After ether, the medulla has been so much overstimulated that the danger of secondary depression when the patient returns to bed is far greater. With ether, toxic symptoms are far more frequent, especially uræmic tendencies and acidosis. The immunity from toxic changes after correct chloroform narcosis has been recently confirmed with care by G. Roello, in the Italian Archives of Surgery, December, 1923, p. 345.

One never sees with 1 per cent. chloroform the steady and needless decline of blood pressure that is so common during the second hour of ether administered by even the most skilful. There is not the same loss of heat.

Horsley was the first to insist on the two-stage operation, an insistence which no one with extensive experience and powers of observation will venture to gainsay.

Thirdly, there should be no such thing as a "dry" brain or spinal cord operation after the dura has been opened. It is synonymous with a shock-producing chill and bloody operation. It has not been an uncommon experience to see surgeons sew back the dura over a bloodflecked cord, or to watch with feelings akin to agony the sponging of the cortex with dry gauze.

Horsley's primary object in allowing frequent lavage of the nerve tissues with 1 in 4,000 bichloride of mercury solution at a temperature of 110 was not antisepsis, as some suppose. This solution is hæmostatic as regards the capillaries, both immediately and later ; it prevents shock by keeping the brain or cord warm, which is a vital matter ; and the method also avoids needless sponging of the brain, which is most obnoxious. Sponsored by so great a physiologist and surgeon as Horsley, I think these points are worthy of more serious consideration. Krause's argument that one cannot tell how much blood is being lost should hardly be regarded seriously, as the lotion is not used until after the scalp and muscles have been dealt with in the "dry" fashion, while the bloodpressure record delivered to the surgeon every few minutes is a better guide in any case than the naked eye.

The same care in recording blood pressure will also convince any one that chloroform is a better anæsthetic for brain operations than ether. 